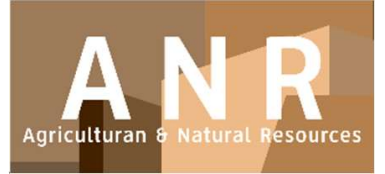

PAPER - OPEN ACCESS

\title{
Karakteristik Biometrik Jenis Shorea Spp Penghasil Tengkawang Dalam Ekosistem Hutan Alam
}

\author{
Author $\quad$ : Farida Herry Susanty dan Deddy Dwi Nur Cahyono \\ DOI $\quad: 10.32734 /$ anr.v3i1.838 \\ Electronic ISSN : :2654-7023 \\ Print ISSN $\quad: 2654-7015$
}

Volume 3 Issue 1 - 2020 TALENTA Conference Series: Agriculturan \& Natural Resource (ANR)

\section{(c) $(1) \Theta$}

This work is licensed under a Creative Commons Attribution-NoDerivatives 4.0 International License.

Published under licence by TALENTA Publisher, Universitas Sumatera Utara

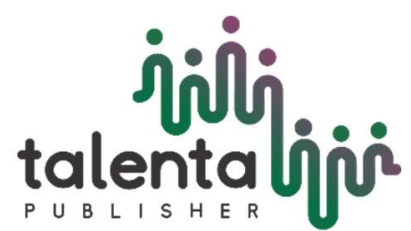




\title{
jibli (4) TALENTA Conference Series
}

Available online at https://talentaconfseries.usu.ac.id/anr

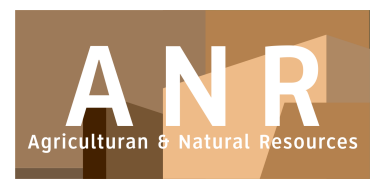

\section{Karakteristik Biometrik Jenis Shorea Spp Penghasil Tengkawang Dalam Ekosistem Hutan Alam}

\author{
Farida Herry Susanty ${ }^{\mathrm{a}}$ dan Deddy Dwi Nur Cahyono ${ }^{\mathrm{b}}$ \\ ${ }^{a}$ Balai Besar Litbang Ekosistem Hutan Dipterokarpa \\ ${ }^{b}$ Balai Litbang Teknologi Perbenihan Tanaman Hutan
}

\begin{abstract}
Abstrak
Klasifikasi jenis/kelompok jenis pohon berdasarkan karakteristik biometrik yang mencakup dimensi biologi baik anatomi maupun fisiologi sangat dibutuhkan. Pola respon lingkungan merupakan sesuatu yang khas untuk dapat memberikan rekomendasi pemilihan jenis yang berpotensi untuk dikembangkan. Penelitian ini bertujuan memperoleh karakteristik biometrik dan kategorisasi jenis Shorea spp. penghasil tengkawang secara kuantitatif dalam ekosistem hutan alam. Pengumpulan data tegakan dilakukan dengan pendekatan purposive terhadap sebaran jenis-jenis Shorea spp. penghasil tengkawang di 2 lokasi di Kalimantan Timur yaitu KHDTK Labanan dan areal pengusahaan PT. Hutan Sanggam Labanan Lestari, serta data analisis riap jenis dari petak ukur permanen. Dari hasil penelitian, ditemukan sebanyak 5 jenis dengan 163 pohon sampel yang terdiri dari Shorea pinanga, Shorea palembanicus, Shorea macroptera, Shorea macrophylla dan Shorea beccariana. Sebaran diameter cukup merata yaitu pada kisaran 12-70 cm. Penilaian karakteristik biometrik pohon berdasarkan pengelompokkan berdasarkan rasio antar dimensi pohon diameter setinggi dada (dbh), tinggi bebas cabang (tbc) dan tinggi total (ttot). Rasio dimensi pohon kelompok jenis ini mempunyai kecenderungan yang sama terutama untuk skala rasio dbh:tbc $=1.1-1.99$ dan tbc:ttot $=0.6-0.79$. Sedangkan rasio dbh:ttot cukup bervariasi. Rekomendasi pengembangan untuk kelompok jenis ini adalah Shorea pinanga dan Shorea macroptera.
\end{abstract}

Kata Kunci: Karakteristik biometrik; Kelompok Jenis; Shorea; Tengkawang; Rasio dimensi

\section{Pendahuluan}

Karakteristik biometrik pohon merupakan sifat-sifat atau ciri-ciri biologi yang spesifik dari dimensi suatu jenis atau kelompok jenis pohon, dengan ukuran (metrik) yang bersifat kuantitatif (skala rasio dan interval), mencakup dimensi biologi baik anatomi maupun fisiologi serta pola respon sebagai sesuatu yang khas. Dalam upaya menjelaskan bagaimana korelasi dimensi-dimensi dasar pada berbagai jenis pohon dapat dihubungkan dalam suatu kondisi tegakan hutan alam. Karena lebarnya variasi kombinasi, hingga kini belum dapat ditentukan fungsi dimensi yang lebih dominan [1]-[3]. Bentuk hubungan tiap dimensi bersifat khas untuk setiap jenis pohon. Klasifikasi pohon secara ekologi (pohon, tiang, semai dan pancang) perlu ditinjau berdasarkan karakteristik biometrik jenis yang memenuhi bentuk fisiologi yang unik dan konstan atau bersifat kuantitatif etnobiologi sehingga ditemukan bentuk klasifikasi skala rasio dari pertumbuhan pohon.

Pertumbuhan individu pohon atau penyusun tegakan merupakan total interaksi yang diperoleh dari sifat genetik dan lingkungannya [4]. Pola pertumbuhan individu pohon sangat dipengaruhi oleh faktor lingkungan dan ruang tumbuh akan membentuk pertumbuhan tegakan yang berbeda [5]-[7].

Hutan hujan tropika dataran rendah merupakan hutan alam dengan karakteristik tegakan yang khas dengan keragaman jenis yang terbesar di dunia [8]-[9] juga pada tingkat perkembangan dan variasi dimensi tegakan [10]. Tingkat keragaman jenis suatu vegetasi merupakan hasil dari proses ekofisiologis yang dinamis yaitu mempunyai 
korelasi dengan kondisi iklim setempat, kondisi hara, rentang toleransi jenis, faktor biogeografi atau sebaran jenis dan variasi kondisi ekologi hutan [11]. Hutan tropika dataran rendah di Asia Tenggara didominasi oleh famili Dipterocarpaceae sehingga sering disebut sebagai hutan Dipterocarpaceae campuran [8]-[9] atau hutan Dipterocarpaceae [12]. Hutan Dipterocarpaceae campuran di wilayah Malesia Barat merupakan tipe hutan tropis paling produktif berdasarkan nilai kayunya. Di Indonesia, famili Dipterocarpaceae mempunyai kontribusi terbesar (lebih dari 25\%) sebagai kayu komersial hutan alam dengan volume antara 50-100 $\mathrm{m}^{3}$ ha-1 terutama untuk wilayah hutan di Kalimantan [13].

Pentingnya tinjauan respon individu pohon sebagai penyusun dalam tegakan yang beragam akan dapat memberikan rekomendasi pemilihan jenis. Belum tersedianya data dan informasi mengenai karakteristik jenis pohon Dipterocarpaceae terutama kelompok jenis tengkawang di alam secara alami menjadi hambatan dalam pemilihan jenis yang berpotensi dikembangkan. Sehingga penelitian ini bertujuan memperoleh karakteristik biometrik dan kategorisasi jenis Shorea spp. penghasil tengkawang secara kuantitatif dalam ekosistem hutan alam.

\section{Metode Penelitian}

\subsection{Lokasi Penelitian}

Pengumpulan data tegakan dilakukan dengan pendekatan purposif terhadap sebaran jenis-jenis Shorea spp. penghasil tengkawang yang berada di 2 lokasi yaitu KHDTK Labanan dan areal pengusahaan PT. Hutan Sanggam Labanan Lestari, Kabupaten Berau Kalimantan Timur. Data yang diperoleh didukung dengan hasil analisis riap jenis dari data pengukuran tegakan jenis pada petak ukur permanen yang ada pada KHDTK Labanan.

\subsection{Obyek dan Alat}

Obyek penelitian adalah jenis-jenis Dipterocarpaceae dalam ekosistem hutan alam. Sedangkan peralatan yang dipergunakan meliputi alat pengumpulan data lapangan, pengukuran pohon, pengambilan sampel jenis dan alat pengolah data.

\subsection{Prosedur Kerja}

Pengumpulan data tegakan dilakukan dengan pendekatan plot sampling secara purposive terhadap distribusi jenisjenis Dipterocarpaceae. Plot sampling dibangun pada berbagai variasi kondisi hutan untuk memperoleh varian karakteristik biometrik jenis. Kegiatan utama meliputi:

1. Identifikasi jenis pohon sampel (tenaga botanis dan laboratorium),

2. Pengumpulan data berdasarkan teknik survey secara purposive terhadap kelompok jenis Dipterocarpaceae,

3. Pengukuran dimensi pohon sampling (diameter, tinggi) dan data tegakan pada plot sampling meliputi data: nama jenis pohon, keliling batang (setinggi dada $1.3 \mathrm{~m}$ atau $20 \mathrm{~cm}$ di atas banir), posisi pohon dalam plot.

4. Pengumpulan dan pengukuran data tegakan pada plot permanen untuk data riap diameter individu jenis.

\subsection{Analisis Data}

Penilaian karakteristik dimensi kuantitatif individu jenis berdasarkan analisis variabel dimensi yang meliputi:

1. Distribusi diameter jenis/kelompok jenis dalam tegakan hutan alam

2. Rasio dbh/tbc

3. Rasio dbh/ttot

4. Rasio tbc/ttot 


\section{Hasil dan Pembahasan}

Pengambilan data pohon sampel dilakukan pada 2 lokasi yaitu KHDTK Labanan dan Hutan Sanggam Labanan Lestari yang keduanya termasuk dalam kawasan KPH Berau barat. Dari kedua lokasi tersebut diperoleh 1.463 pohon sampel yang terdiri dari 60 jenis famili Dipterocarpacea. Berdasarkan rekapitulasi, jenis Shorea parvifolia memiliki jumlah terbanyak yang teridentifikasi. Jumlah terbanyak selanjutnya adalah Shorea beccariana dan Shorea macroptera.

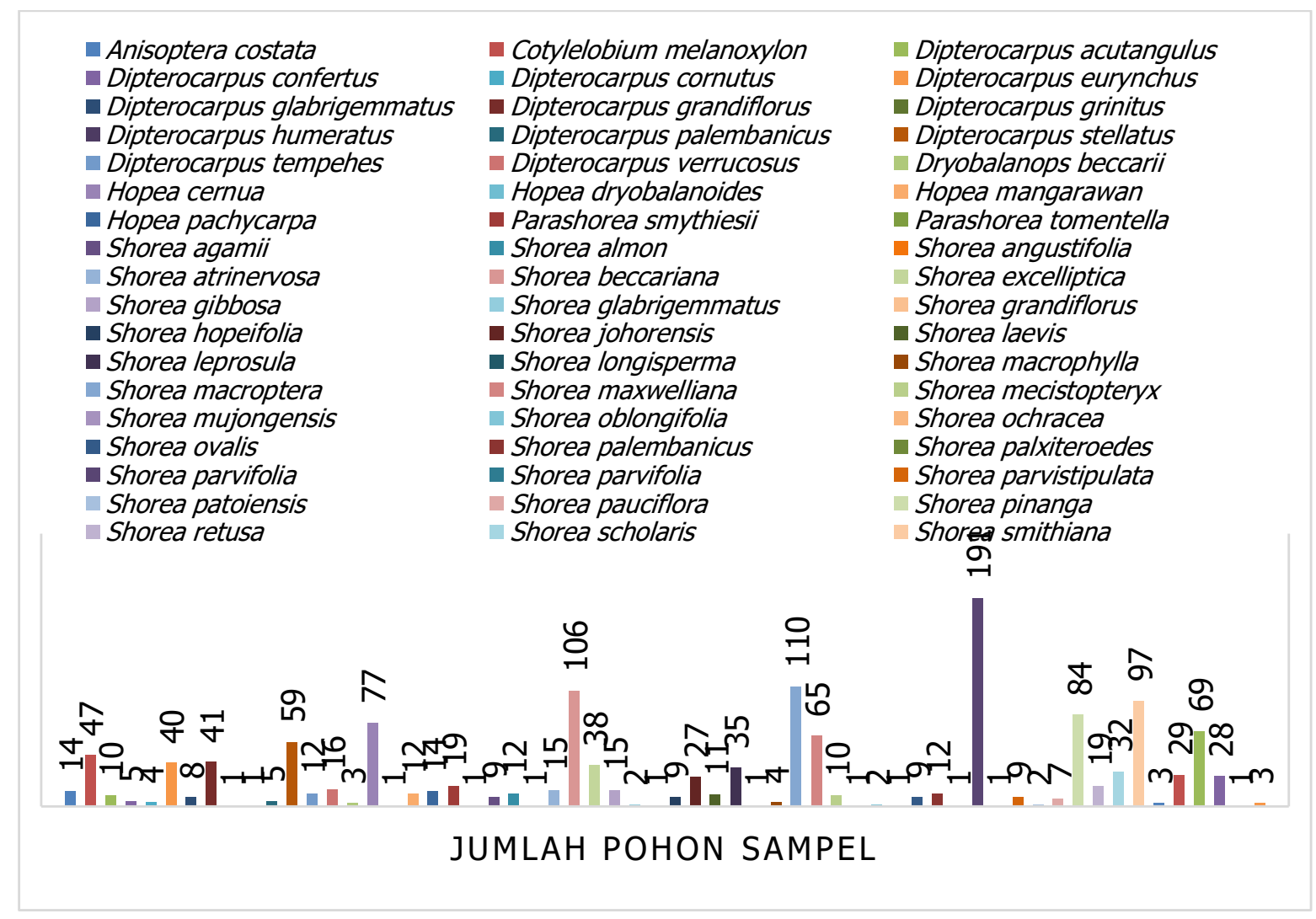

Gambar 1. Rekapitulasi 60 jenis dari famili Dipterocarpaceae

Berdasarkan hasil rekapitulasi diatas, pola sebaran pohon sampel berdasarkan diameter dapat diperoleh. Melalui distribusi diameter pohon sampel tersebut, dapat diketahui bahwa pola distribusi kelas diameter pohon pada plot pengamatan ditemukan jumlah individu pohon terbanyak yaitu pada diameter kecil dan semakin berkurang dengan bertambahnya ukuran diameter pohon sampel. Walapun demikian distribusi diameter terlihat merata dengan kisaran diameter $11 \mathrm{~cm}-100 \mathrm{~cm}$. 


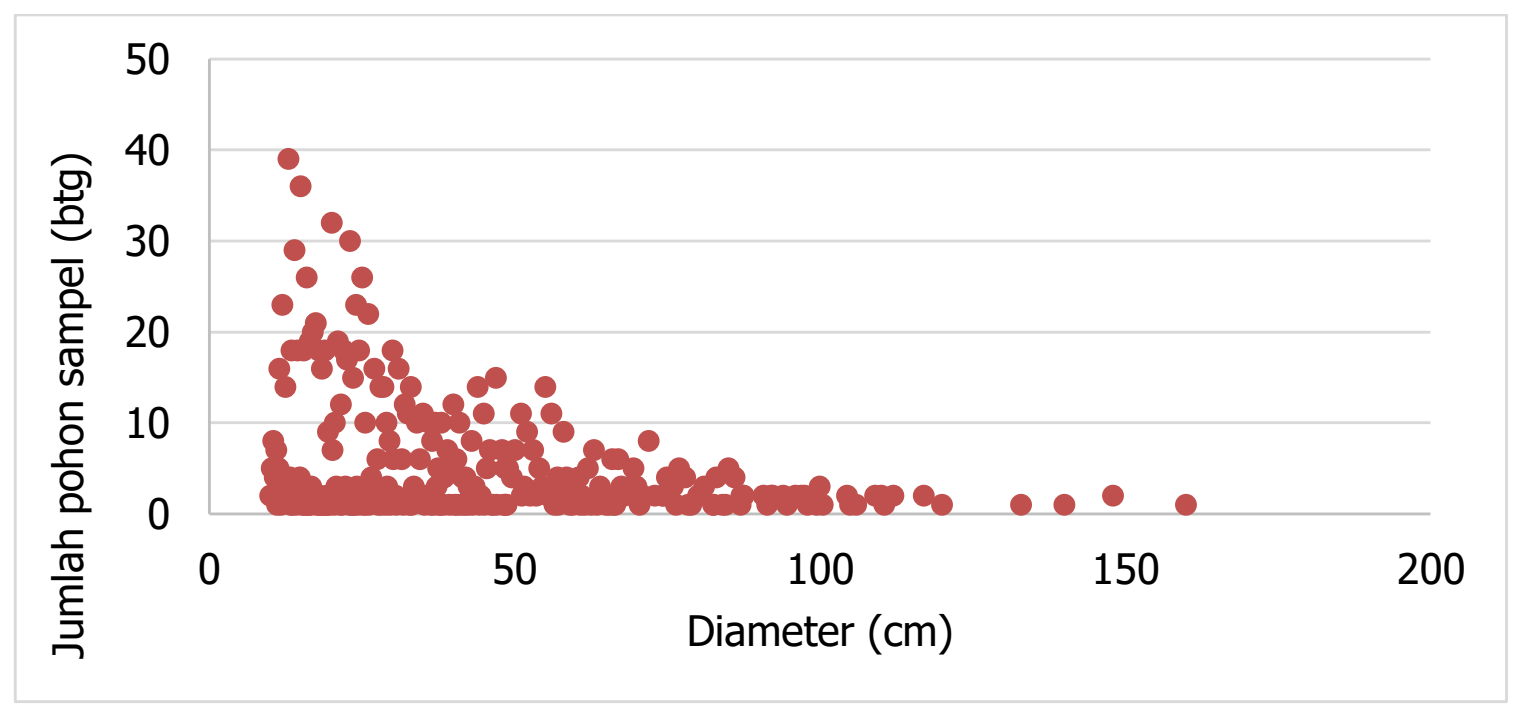

Gambar 2. Distribusi diameter pohon sampel Dipterocarpaceae

Dari seluruh pohon sampel yang telah diperoleh, untuk melakukan analisis maka pengelompokkan dilakukan pada jenis tengkawang dan terdapat 6 jenis dengan 163 pohon sampel (Gambar 3) yang terdiri dari Shorea pinanga, Shorea palembanicus, Shorea macroptera, Shorea macrophylla dan Shorea beccariana untuk dilakukan analisis vegetasi dan analisis dimensi tegakan. Dari keenam jenis tersebut, distribusi diameter pohon tengkawang dapat diketahui dan tersaji pada Gambar 4.

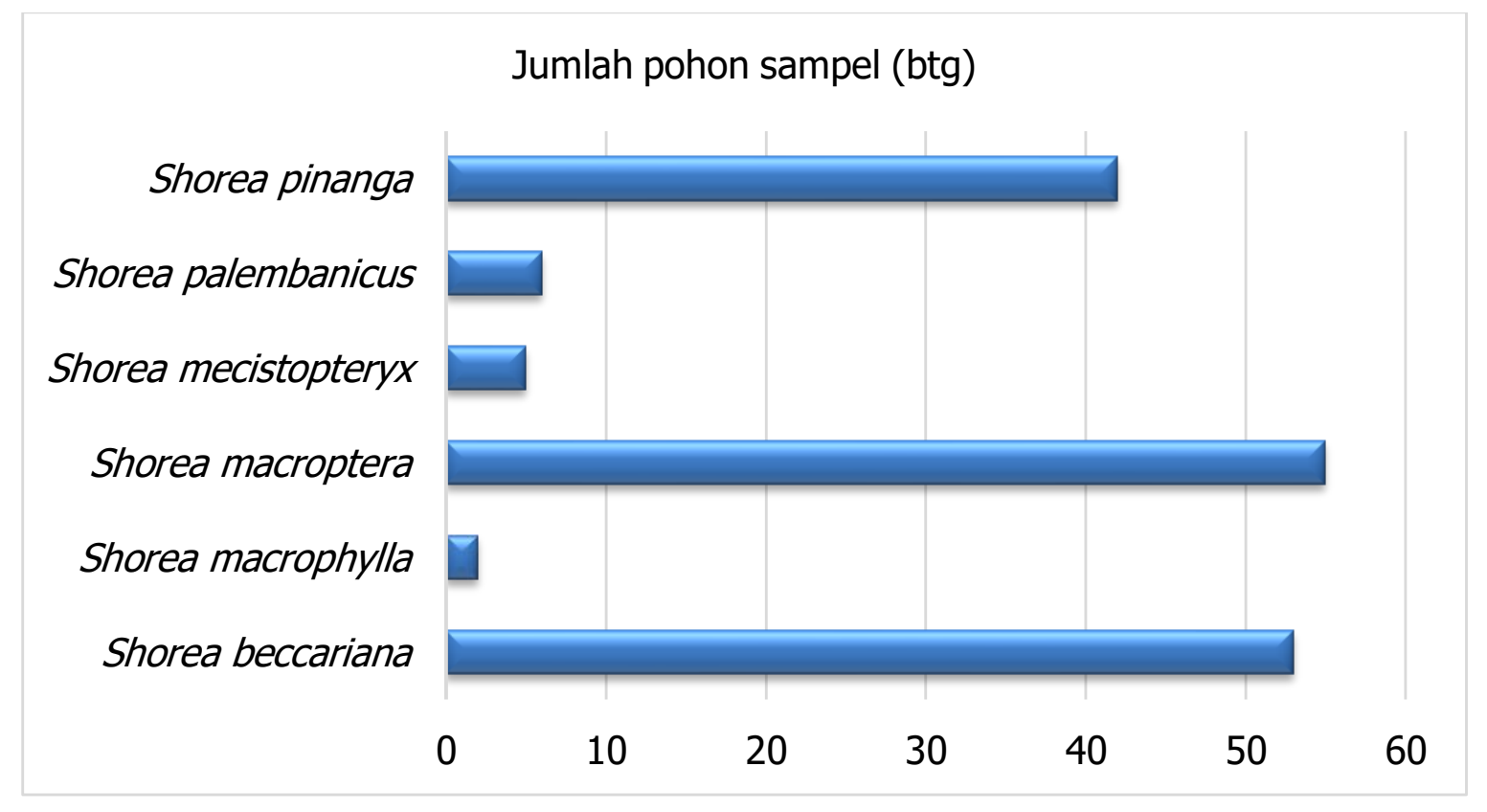

Gambar 3. Jumlah pohon sampel. 


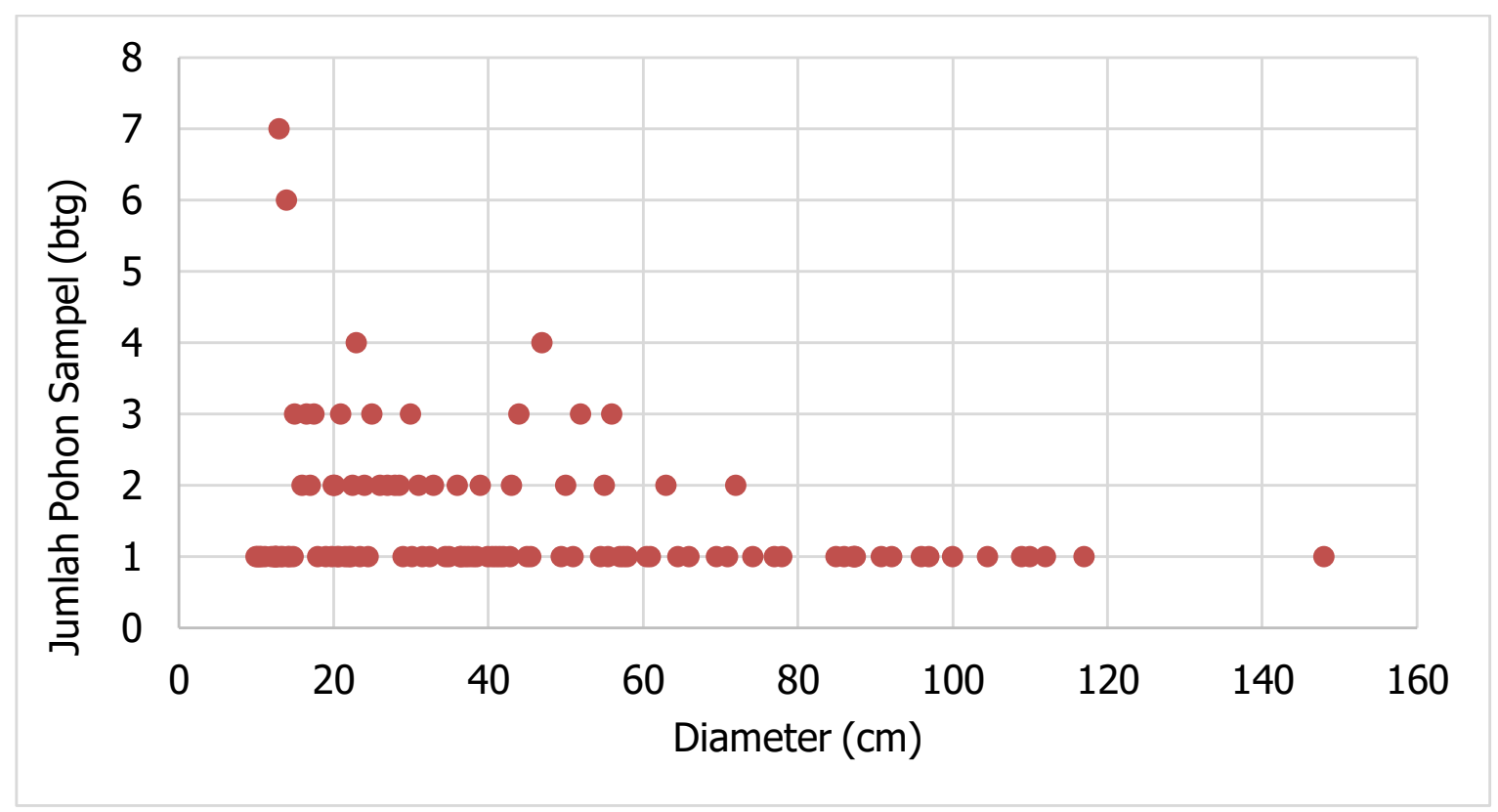

Gambar 4. Distribusi pohon sampel jenis tengkawang.

Berdasarkan diagram di atas, jumlah pohon dengan diameter kecil berjumlah lebih banyak dan semakin berkurang seiring bertambahnya ukuran diameter pohon. Namun diameter tersebar cukup merata pada kisaran $12-70 \mathrm{~cm}$. Hasil perhitungan skala rasio dimensi kuantitatif jenis Shorea spp penghasil tengkawang disajikan pada tabel 1, 2 dan 3 sebagai berikut.

Tabel 1. Skala rasio DBH/Tbc

\begin{tabular}{llllll}
\hline Jenis & $<1.0$ & $1.1-1.9$ & $2-2.99$ & $3-3.9$ & $4-4.9$ \\
\hline Shorea beccariana & 4 & 20 & 16 & 4 & - \\
Shorea macrophylla & - & 1 & - & - & - \\
Shorea macroptera & - & 22 & 18 & 4 & - \\
Shorea mecistopteryx & & 1 & 2 & 2 & - \\
Shorea palembanica & - & 5 & - & - & 3 \\
Shorea pinanga & 4 & 18 & 6 & 7 & \\
\hline
\end{tabular}

Tabel 2. Skala rasio DBH/Ttot

\begin{tabular}{llllll}
\hline Jenis & $<0.5$ & $0.6-1.19$ & $1.2-1.79$ & $1.8-2.39$ & $2.4-3$ \\
\hline Shorea beccariana & - & 18 & 26 & 6 & 6 \\
Shorea macrophylla & - & 1 & - & - & - \\
Shorea macroptera & - & 20 & 24 & 6 & 2 \\
Shorea mecistopteryx & - & 1 & - & - & 1 \\
Shorea palembanica & - & 5 & 1 & 6 & - \\
Shorea pinanga & 1 & 21 & 5 & 6 \\
\hline
\end{tabular}


Tabel 3. Skala rasio Tbc/Ttot

\begin{tabular}{llllll}
\hline Jenis & $<0.2$ & $0.2-0.39$ & $0.4-0.59$ & $0.6-0.79$ & $0.8-0.99$ \\
\hline Shorea beccariana & - & 1 & 5 & 27 & 15 \\
Shorea macrophylla & - & - & - & 1 & - \\
Shorea macroptera & - & 2 & 8 & 34 & 9 \\
Shorea mecistopteryx & - & - & - & 4 & 1 \\
Shorea palembanica & - & - & - & 31 & 2 \\
Shorea pinanga & - & 1 & 3 & & 4 \\
\hline
\end{tabular}

Berdasarkan kecenderungan dan konsistensi bentukan secara karakteristik kuantitatif, dapat dikelompokkan bahwa jenis yang sama adalah jenis $S$. beccariana, $S$. macroptera dan $S$. pinanga. Kondisi rasio ini menunjukkan bentuk visual batang dari suatu jenis di alam. Beberapa upaya untuk menjelaskan bagaimana dimensi-dimensi dasar pada berbagai jenis dihubungkan dalam tegakan yang sama. Secara prinsip, fungsi korelasi dapat diestimasi untuk semua kombinasi diameter. Lebarnya variasi kombinasi, menyebabkan fungsi dimensi yang lebih dominan belum dapat ditentukan [1]. Beberapa upaya analisis pola ragam yang diformulasikan dalam upaya menemukan ragam yang khas secara kuantitatif pada setiap jenis atau kelompok jenis masih sangat terbatas [14],[2],[15],[3].

Penilaian individu secara kuantitatif dengan variasi kondisi tegakan hutan alam yang berbeda menunjukkan respon yang berbeda terhadap jenis/kelompok jenis. Pendekatan pengelompokkan jenis atau dimensi tegakan yang berbeda dapat dilakukan untuk melihat variasi pengaruh atau respon kelompok jenis terhadap variasi kondisi tegakan hutan [16]; [17]. Respon yang berbeda dari jenis atau kelompok jenis merupakan salah satu tinjauan karakteristik penilaian kuantitatif dimensi tegakan yang penting untuk pertimbangan variasi keragaman jenis penyusun tegakan [18]; [19].

\section{Kesimpulan}

Enam jenis tengkawang berhasil teridentifikasi yaitu: Shorea beccariana, Shorea pinanga, Shorea macrophylla, Shorea macroptera, Shorea mecistopterix, Shorea palembanica. Rasio dimensi tegakan jenis tengkawang berdasarkan diameter setingi dada: tinggi bebas cabang, diameter setinggi dada: tinggi total dan tinggi bebas cabang: tinggi total dalam 5 kelas pengelompokkan. Berdasarkan karakteristik biometrik batang yang berada dalam satu kelompok jenis dengan pola kecenderungan yang sama yaitu jenis S. beccariana, S. macroptera dan S. pinanga.

\section{Ucapan Terima Kasih}

Penelitian dilakukan dengan dana DIPA Balai Besar Penelitian dan Pengembangan Bioteknologi dan Pemuliaan Tanaman Hutan (BBPPBPTH). Terima kasih penulis sampaikan kepada semua pihak yang telah membantu dalam pelaksanaan penelitian dan penyediaan referensi dalam penulisan naskah.

\section{Referensi}

[1] J. Lappi, A Multivariate (2006) "Non-parametric Stem-Curve Prediction Method", Canada, NRC Research Press Web

[2] Maulidian (2007) "Karakteristik Biometrik Pohon Belian (Eusideroxylon zwageri T. et B.) pada Tegakan Hutan Sumber benih Plomas Sanggau, Kalimantan Barat", dalam Skripsi Departemen Manajemen Hutan. Fakultas Kehutanan, Institut Pertanian Bogor, Bogor

[3] I. Novendra (2008) "Karakteristik Biometrik Pohon Jati (Tectona grandis Lf.) Studi Kasus di Bagian Hutan Bancar KPH Jatirogo Perum Perhutani Unit II, Jawa Timur", dalam Skripsi Departemen Manajemen Hutan Fakultas Kehutanan, Institut Pertanian Bogor, Bogor

[4] B. T. K. J. J. Husch B. (2003) "Forest Mensuration. Fourth Edition”, New Jersey (US), John Wiley \& Sons Inc.

[5] L. B. Oliver C.D. (1990) "Forest Stand Dynamics", New York (US), McGraw Hill Inc.

[6] K. T. Adams H.D. (2005) "Tree growth response to drought and temperature in a mountain landscape in Northern Arizona, USA." J Biogeogr. 32: $1629-1640$.

[7] O. K. Gersonde R.F. (2005) “Comparative tree growth efficiency in Sierra Nevada mixed-conifer forests.” Forest Ecol Manag. 219: 95-108. 
[8] R.P.W. (1964) “The Tropical Rain Forest. An Ecological Study”, New York (US), Cambridge at The University Press Company

[9] W.T.C. (1990) "Tropical rain forest dynamics and its implications for management”, dalam Gomez-Pompa A., Whitmore T.C., Hadley M. (eds) Rain Forest Regeneration and Management. Man and the Biosphere Series 6: 67-89, Paris (FR), Parthenon Publishing Group

[10] M. Prodan (1986) "Forest Biometrics", in translated by Sabine H. Gardiner, Oxford, Pergamon Press

[11] D. S. L. J. T. S. I. A. Y. T. O. T. A. P. Lee H.S. "Floristic and structural diversity of mixed dipterocarp forest in Lambir Hills National Park, Sarawak, Malaysia." J Trop For Sci. 14 (3): 379-400.

[12] A.P.S. (1982) "Dipterocarpaceae", FMales

[13] F. R. S. D. N. R. C. M. Sist P. (2003) "Towards sustainable management of mixed Dipterocarp forests of South-East Asia: Moving beyond minimum diameter cutting limits", Environ Conserv. 30 (4): 364-374.

[14] Muhdin (2003) “Dimensi Pohon dan Perkembangan Metode Pendugaan Volume Pohon. Pengantar Falsafah Sains”, Institut Pertanian Bogor., Bogor

[15] S. Wijayanti (2008) "Karakteristik Biometrik Pohon Agathis loranthifolia R.A. Salisbury di BPKH Gunung Slamet Barat KPH Banyumas Timus Perum Perhutani Unit I Jawa Tengah. Skripsi”, Departemen Manajemen Hutan. Fakultas Kehutanan, Institut Pertanian Bogor, Bogor

[16] B. C. F. M. G. J. M. P. E. I. Harcombe P.A. (2002) "Stand dynamics over 18 years in a Southern Mixed Hardwood Forest, Texas, USA", $J$ Ecol. 90: 947-957.

[17] W. R. S. M. M. M. Seng H.W. (2004) "The effects of the timing and method of logging on forest structure in Peninsular Malaysia", Forest Ecol Manag. 203: 209-228.

[18] Y. I. B. T. v. G. P. Phillips P.D. "Grouping tree species for analysis of forest data in Kalimantan (Indonesian Borneo)", Forest Ecol Manag 157: 205-216, 2002.

[19] M. S. E. V. J. G. M. S. Valle D. (2006) "Identifying bias in stand-level growth and yield estimations: A case study in Eastern Brazilian Amazonia," Forest Ecol Manag. 236: 127-135. 